ECCOMAS

Proceedia
COMPDYN 2017

$6^{\text {th }}$ ECCOMAS Thematic Conference on Computational Methods in Structural Dynamics and Earthquake Engineering

M. Papadrakakis, M. Fragiadakis (eds.)

\title{
THREE-DIMENSIONAL NUMERICAL MODELING OF SEISMIC WAVE PROPAGATION IN WUDU BASIN, CHINA
}

\author{
Xiaolong Zhang ${ }^{1}$, Xiaojun $\mathrm{Li}^{2}$, Zhenghua Zhou ${ }^{1}$, Guoxing Chen ${ }^{1}$, \\ Xiaobo Peng ${ }^{3}$, and Ming $\mathrm{Lu}^{4}$ \\ ${ }^{1}$ College of Transportation Science \& Engineering Nanjing Tech University \\ No.200, Zhongshan North Road, Gulou District, Nanjing, Jiangsu Province 210009, China \\ e-mail: zxlnjut@163.com; bjsmoc@163.com; Gxc6307@163.com \\ ${ }^{2}$ Institute of Geophysics, China Earthquake Administration \\ No.5 Minzudaxue Nanlu, Haidian District, Beijing 100081, China \\ e-mail: beerli@vip.sina.com \\ ${ }^{3}$ Institute of Earthquake Engineering of Jiangsu Province \\ No.3 Weigang road, Xuanwu District, Nanjing, Jiangsu Province 210014, China \\ e-mail: xiaobo_peng@163.com \\ ${ }^{4}$ Institute of Crustal Dynamics, China Earthquake Administration, Beijing,China \\ No.1 Anningzhuang Rd., Xisanqi, Haidian District, Beijing 100085, China \\ e-mail: luming6@yeah.net \\ Correspondence should be addressed to Xiaojun Li; beerli@vip.sina.com
}

Keywords: Basin effect, Numerical modeling, Viscous-elastic Artificial boundary, Incident wave, Site Amplification

\begin{abstract}
.Abstract. The Mw 7.9 earthquake occurred in Wenchuan, Sichuan, China, on 12 May 2008, and it caused huge casualties, economic loss, and serious damage to engineering structures and infrastructures in the area near the fault rupture. In particular, the Wudu township far away from the fault rupture (>100km), which is located in a sedimentary basin, also suffered serious damage, and was in the area with seismic intensity VIII-IX in the Isoseismal Map of Wenchuan Earthquake. In this study, full elastic wave field simulations in the Wudu Basin were conducted by using a three-dimensional (3D) finite element method based on the parallel computing cluster platform of the ABAQUS software. The 3D Wudu Basin model is constructed based on the the digital terrain data borehole spatial distribution data in regional geological survey. The basin model consists of four major subsurfaces and the basin basement, All calculations were executed in the time domain, and the soil and rock were assumed to be linearly elastic. The viscous spring artificial boundary was adopted as the artificial condition, and the incident wave was transformed into the equivalent nodal forces acting on the viscous spring artificial boundary of the finite model. In the simulation, an impulse with a duration of $0.25 \mathrm{~s}$ was taken as the input $S V$ wave. The simulating results of seismic response
\end{abstract}


characteristics varying greatly from different points in the Wudu Basin revealed the basin edge effect, and the basin-focusing effect. The surface wave generated after the primary $S$ wave is trapped at the shallow part of the basin, and most of the energy is reflected from the interfaces of soil strata and focused back into the basin when the wave propagates through the deepest part of the basin. Moreover, a part of the seismic wave front turns and follows the shallow basin edge, resulting in further amplification. The phenomenon, that is the incident angle of the seismic waves can produce unusually strong shaking distribution, was demonstrated. It indicates that the complex Wudu Basin geometry, the fairly low velocity of the surface soil layer, and the incident angle of seismic waves dominate the amplification and wave propagation behavior, which results in extraordinary strong shaking patterns in the Wudu basin area.

\section{INTRODUCTION}

The Mw 7.9 Wenchuan earthquake occurred in the Longmen Mountain region at the eastern margin of the Qinghai-Tibet Plateau, which is adjacent to the Sichuan Basin (Fig. 1), on 12 May 2008. The Wenchuan earthquake caused significant building damage and collapse with considerable casualties, but it also provided most of the best data to investigate many fundamental problems of wave propagation in the heterogeneous crust. The Wudu township, which is located in a sedimentary basin in northern Jiangyou situated in the eastern YingxiuBeichuan Fault, also suffered serious earthquake damage. Previous studies concerning basins indicated that low-velocity soil layer and basin geometry have a strong influence on the behavior of seismic wave propagation (Alex and Olsen, 1998; Davis et al., 2000) and strengthen the shaking activity (Graves 1998; Olsen, 2000; Komatitsch et al., 2004). The cover soil layer in the Wudu Basin is thin, with a relative depth of approximately $20 \mathrm{~m}$ and a fairly low $\mathrm{S}$ wave velocity, which makes it particularly vulnerable to severe earthquake damage.

Surface topography can significantly affect ground motion characteristics. An irregular free surface can further lead to complex wave propagation. Structures located at the tops of hills, ridges, and canyons may suffer more intensive damage than structures situated at the bases of hills or on level surfaces, as observed from earthquakes and from numerical simulations (Hartzell et al., 1994; Spudich et al., 1996; Assimaki et al., 2005). In the past decades, seismologists and engineers made significant progress in simulating ground motion using a variety of simplified numerical and analytical methods, such as one-dimensional and twodimensional local site models. These models can assist in explaining the observed phenomena in certain situations. However, observations of ground motion during recent strong earthquakes have shown that the three-dimensional (3D) local site effects may be extremely important and may adversely affect structural safety. Three common effects often observed in basins or sedimentary valleys are amplification of strong motion intensity, significantly long duration of the surface ground motion with respect to that of the rock, and rapid spatial variation of the ground motion.

Recently, various numerical studies of seismic wave propagation in 3D sedimentary basins have demonstrated substantial progress using parallel computer facilities. The most widely used approach for modeling of seismic wave propagation is the finite difference method (FDM) (Pitarka, 1999; Olsen, 2000; Kristek et al., 2009). However, realistic topography was frequently not considered in simulations because of the difficulty of incorporating the free surface boundary condition in the FDM in the presence of topography (Moczo et al., 2007). Since the 1990s, the finite element method (FEM) (Liu et al., 1991; Bao et al., 1998; Ma et al., 2007; Taborda et al., 2012) has been applied to the study of wave propagation in realistic models, including 3D sedimentary basins. However, large systems require iterative routines, 
which may increase the cost of the calculations, particularly in the case of realistic 3D problems. From the spectral approximations of the wave field combined with domain decomposition techniques, simulations of earthquake ground motion using the spectral element method (SEM) rapidly advanced in recent years. The application of SEM to elastodynamic problems was first presented by Faccioli et al. (1997) and applied by Lee et al. $(2008,2009)$ to realistic models. Such studies are highly useful in understanding the physics of site response. From these analyses, knowledge of the topographic effects on seismic wave propagation and the amplification of seismic waves at a topographic site is obtained; so far, these models are solved only for low frequencies to render the numerical problem as tractable. No seismic waves of up to a maximum frequency of $5 \mathrm{~Hz}$ are detected. However, realistic 3D basin models must be considered and evaluated at high frequencies, which are important in engineering design, to model the actual seismic hazard.

The FEM is used to simulate seismic wave propagation in the Wudu area to accommodate the considerable surface topography and the highly variable low-wave speed sedimentary basin in this study. The pretreatment software HyperMesh was employed to structuralize the geometric model and the grid partition. With this software, realistic topography and complex subsurface structures can be efficiently incorporated with the FEM mesh, the resolution of the subsurface structure can reach up to $2.5 \mathrm{~m}$, and a high frequency (up to $10 \mathrm{~Hz}$ ) of the synthetic waveform can be achieved. Four incident angles of the same seismic waves are analyzed to distinguish the case of the amplification effects. Although numerical simulations with simple incident pulses are not as powerful as the simulations from the real earthquake strong motion, the corresponding results can provide interesting information on the Wudu Basin. These results can also be meaningful for future studies, such as the seismic hazard reduction studies in the metropolitan region.

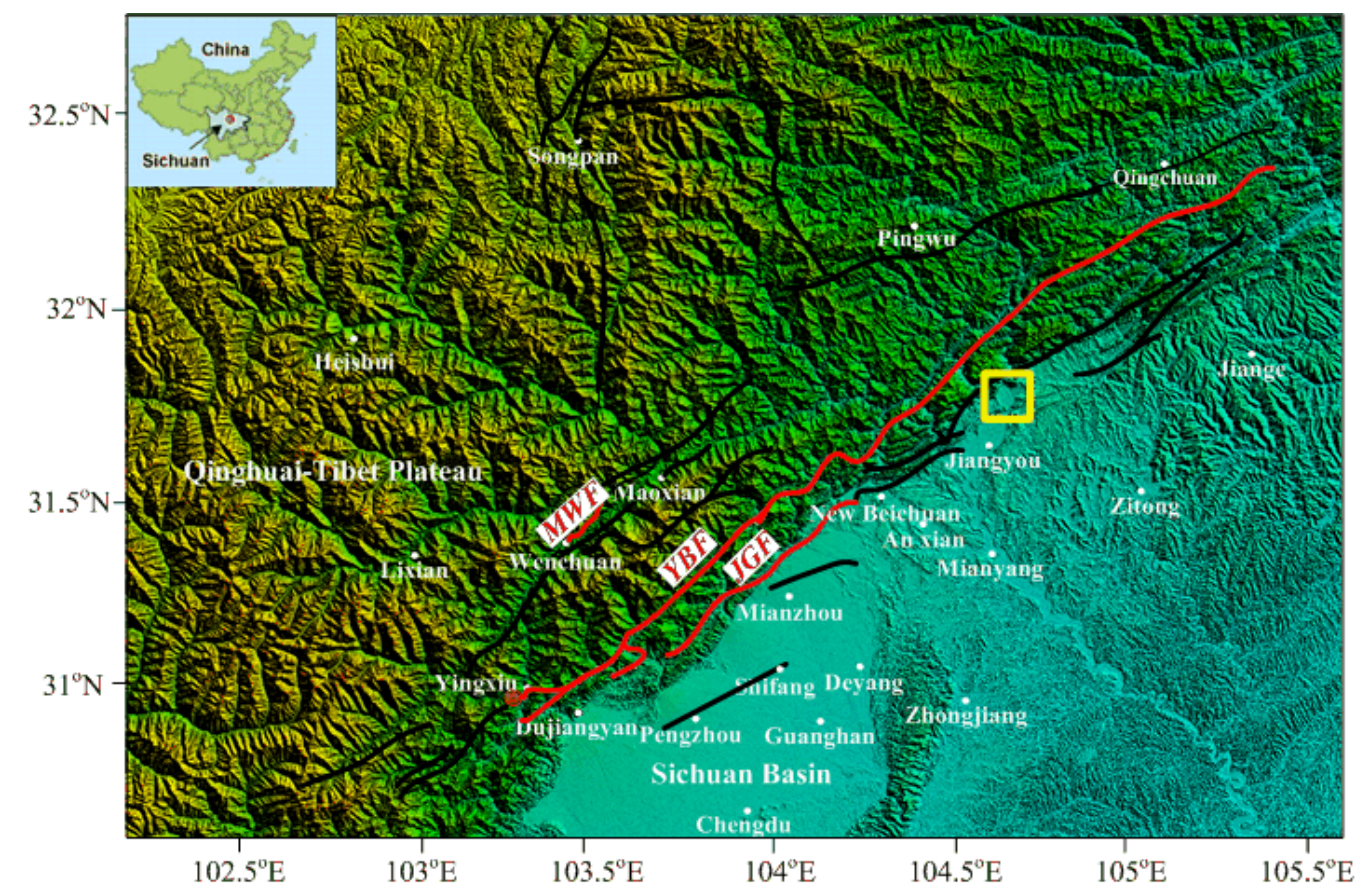

Figure 1.The 2008 Wenchuan earthquake area (The black lines depict the main fault and the red lines is the coseismic rupture. $M W F$ Maoxian-Wenchuan Fault, YBF Yingxiu-Beichuan Fault, JGF Jiangyou-Guanxian Fault. The Yellow rectangle shown the area of wudu basin). 


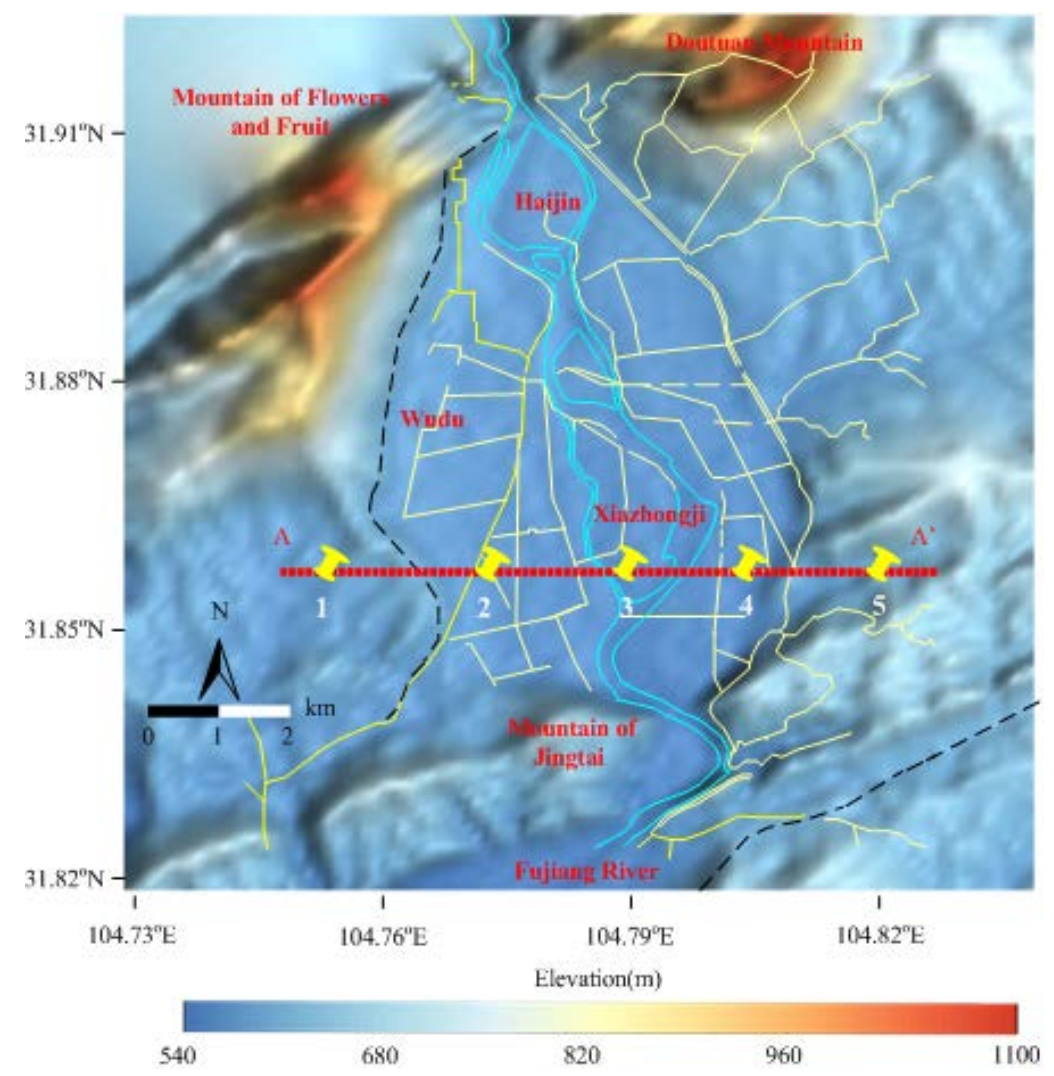

Figure 2. Topographic map of the Wudu basin. The four corners of the area are $\left(31.819^{\circ} \mathrm{N}, 104.730^{\circ} \mathrm{E}\right)$, $\left(31.819^{\circ} \mathrm{N}, 104.836^{\circ} \mathrm{E}\right),\left(31.921^{\circ} \mathrm{N}, 104.836^{\circ} \mathrm{E}\right)$, and $\left(31.921^{\circ} \mathrm{N}, 104.730^{\circ} \mathrm{E}\right)$. The thin yellow lines depict the major highways and the black dashed lines is the railway. The elevation is represented by the rainbow color scale.

\section{WUDU BASIN MODEL AND NUMERICAL METHOD}

\subsection{Realistic Topography and Basin Structure}

The Wudu Basin is located in the northern areas of Sichuan Province, China, lying at $104.728^{\circ}$ to $104.840^{\circ} \mathrm{E}$ longitude and $31.817^{\circ}$ to $31.924^{\circ} \mathrm{N}$ latitude. The Wudu Basin is mainly an alluvial plain with undulating low mountains and interspersed hills (see Fig. 2). From the regional geological survey borehole spatial distribution data, several characteristics can be noted: (1) the Wudu Basin is a shallow dish-shaped basin with a gentle dipping boundary, and the average dipping angle is not more than $45^{\circ} ;(2)$ the deepest part of the basement is probably near the outlet of the Fujiang River in the south area of the basin; and (3) There are four rock and soil layers, in which each layer is in an approximately horizontal distribution. The $P$ and $S$ wave velocities inside the basin are approximately $522 \mathrm{~m} / \mathrm{s}$ to $1,927 \mathrm{~m} / \mathrm{s}$ and $200 \mathrm{~m} / \mathrm{s}$ to $1,065 \mathrm{~m} / \mathrm{s}$, respectively; the velocities of the basin basement beneath and surrounding the basin are 3,956 and $2,250 \mathrm{~m} / \mathrm{s}$, respectively. For the numerical simulations, major continuities separating the layers of homogeneous velocities are used. The detailed material parameters and the grid size of the model are listed in Table 1.

\begin{tabular}{ccccccc}
\hline Depth $(\mathrm{m})$ & $\rho\left(\mathrm{kg} / \mathrm{m}^{3}\right)$ & $E(\mathrm{MPa})$ & $v$ & $C_{p}(\mathrm{~m} / \mathrm{sec})$ & $C_{s}(\mathrm{~m} / \mathrm{sec})$ & Grid size $(\mathrm{m})$ \\
\hline $0-20$ & 1880 & 213 & 0.414 & 522 & 200 & 2.5 \\
$20-40$ & 2250 & 1250 & 0.324 & 897 & 458 & 5 \\
$40-80$ & 2400 & 4025 & 0.3 & 1502 & 803 & 10 \\
$80-120$ & 2580 & 7500 & 0.28 & 1927 & 1065 & 12.5
\end{tabular}




$\begin{array}{lllllll}>120 & 2630 & 32500 & 0.22 & 3756 & 2250 & 25\end{array}$

Table 1: Material parameters and the grid size used in the simulations

\subsection{Finite-Element Model Discretization and Boundary Conditions}

The dimension of the simulated Wudu Basin model is $10 \times 10 \mathrm{~km}$ at the surface and 0.6 $\mathrm{km}$ in depth. The velocity outside the basin is simplified by an assumption of a homogeneous half-space. The FEM is used to simulate seismic wave propagation in the Wudu Basin. The 3D model is established according to the digital terrain model (DTM) data. The pretreatment software HyperMesh is utilized to structuralize the geometric model and grid partition to accommodate the topography and the highly variable low-wave speed sediments in the Wudu Basin.

Mesh generation is the key simulation step, the size of which is selected according to the frequency content of the incident motions and shear wave velocity of the medium considered. For the effective representation of the propagating wavelengths, the finite element grid maximum size at the direction of wave propagation is always set as $1 / 8$ to $1 / 10$ of the minimum wavelength corresponding to the cutoff frequency, which is set as $10 \mathrm{~Hz}$ in this study. Based on this software, realistic topography and complex subsurface structures can be efficiently incorporated with the FEM mesh. The grid space in the shallowest part can reach up to $2.5 \mathrm{~m}$ and a higher frequency (up to $10 \mathrm{~Hz}$ ) of the synthetic waveform can be achieved in the simulation, which yields a total of 189,849,984 elements and 60,825,600 nodes.

Finite element simulation of the time-dependent wave propagation in infinite media requires enforcing the transmitting boundary to replace the truncated far-field infinite domain to model the effect of the wave radiation toward infinity. The artificial boundary condition is always used to absorb the energy of the scattering waves propagating from the generalized structure into the infinite or semi-infinite medium. Because the viscous spring artificial boundary can efficiently simulate radiation damping and elasticity recovery of the infinite and semi-infinite media with good stability and high accuracy (Liu et al., 2006; Du et al., 2006), the $3 \mathrm{D}$ viscous spring artificial boundary was adopted to achieve the half-space simulation outside the basin in this model. This artificial boundary can be achieved by establishing a series of distributed springs and dampers on the truncated boundary of the finite element model, as shown in Figure 3. For the 3D viscous spring artificial boundary, the lumped spring coefficient, $K$, and the lumped damping coefficient, $C$, can be expressed as follows:

In the normal direction

$$
K_{N}=A_{l} \cdot \frac{1}{1+A} \cdot \frac{1+2 G}{r}, \quad C_{N}=A_{l} \cdot B \rho c_{p}
$$

In the tangent direction

$$
K_{T}=A_{l} \cdot \frac{1}{1+A} \cdot \frac{G}{r}, \quad C_{T}=A_{l} \cdot B \rho c_{s}
$$




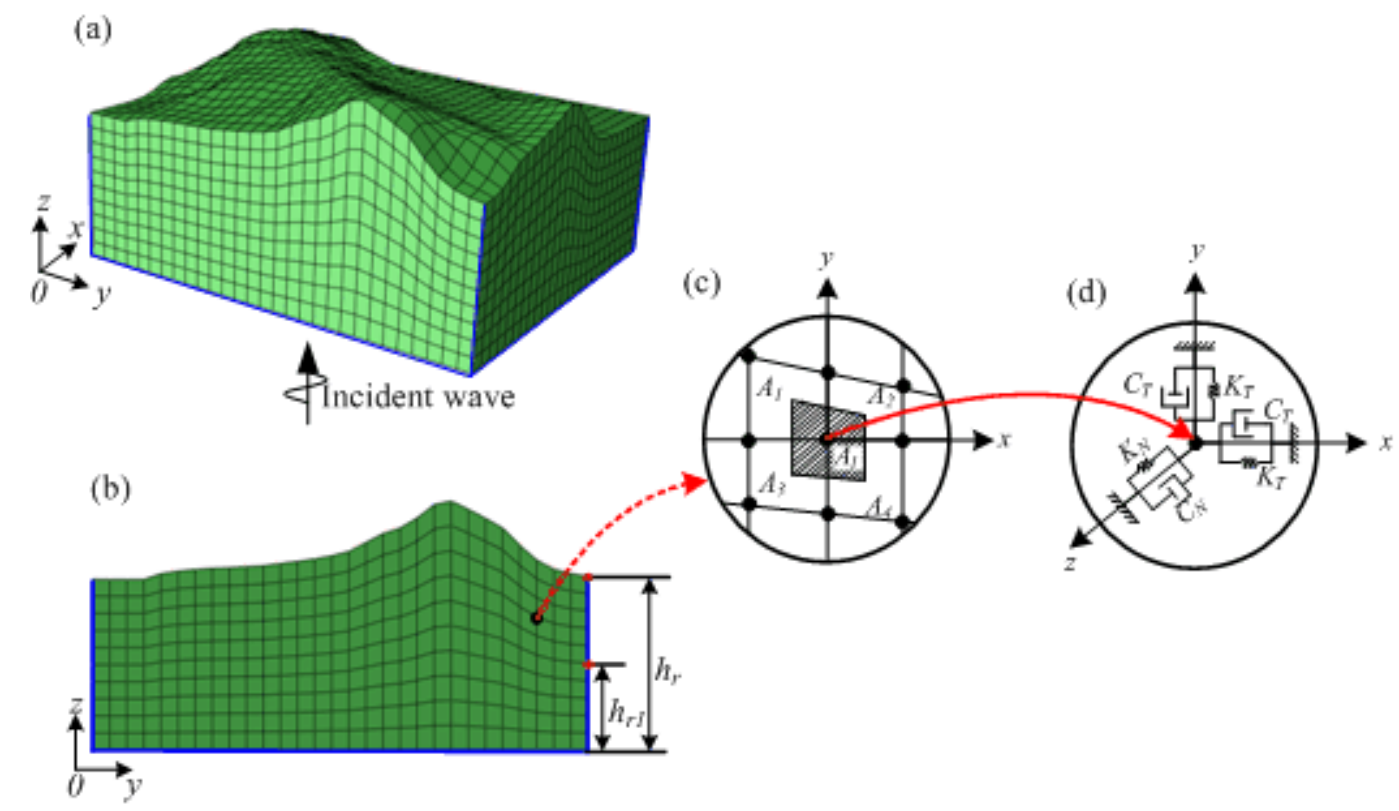

Figure 3. Mechanical model for viscous-spring artificial boundary.

where $r$ is the distance between the center of the surface and the artificial boundary; $c_{s}$ and $c_{p}$ are the velocity of the shear wave and the compression wave in the medium, respectively; $G$ is the shear modulus; $\rho$ is the mass density; $A$ and $B$ are the modified coefficients with good values of 0.8 and 1.1, respectively; and $A_{l}$ is the total truncated boundary area of all elements containing the boundary node $l$. For instance, $A_{l}=\left(A_{1}+A_{2}+A_{3}+A_{4}\right) / 4$ for the status in Figure 3.

\subsection{Wave Input Method Based on Viscous-Spring Boundary}

The seismic motions as the plane body waves with arbitrary incident angle can be converted into the equivalent nodal forces based on the time domain FEM with the viscous spring artificial boundary condition (Liu and Lu, 1998; Liu et al., 2007). According to Liu and Lu (1998), the equivalent node force $f_{l i}$ at direction $i$ of node $l$ can be expressed as:

$$
f_{l i}=K_{l i} u_{l i}^{f}+C_{l i} \dot{u}_{l i}^{f}+A_{l} \sigma_{l i}^{f}
$$

where $K_{l i}$ and $C_{l i}$ are the two parameters of the viscous spring artificial boundary; $A_{l}$ is the total truncated boundary area of all elements containing boundary node $l$; and $u_{l i}^{f}, \dot{u}_{l i}^{f}$, and $\sigma_{l i}^{f}$ represent the displacement, velocity, and stress of input motions, respectively.

For the SV wave input, the key step is converting the input waves into the equivalent nodal forces. In the work of Huang (2015), the equivalent nodal forces of the oblique incidence of seismic waves have been achieved, and the wave input is implemented into the commercial software ABAQUS by a self-developed FORTRAN program. In this study, a Dirac impulse with a duration of $0.25 \mathrm{~s}$ is chosen as the input SV wave (plotted in Fig. 4), and the mesh allows the simulation of the seismic waves up to a maximum frequency of $10 \mathrm{~Hz}$. The seismic wave path in the layered media is related to the velocity in the layers, and the occurrence of subsurface is related to the initial orientation of the rays. According to the geographical location of the Wudu Basin, the response of the basin to a single plane incident SV wave propagation from west to east with four incident angles of $0^{\circ}, 10^{\circ}, 20^{\circ}$, and $30^{\circ}$ in the half-space was computed. 

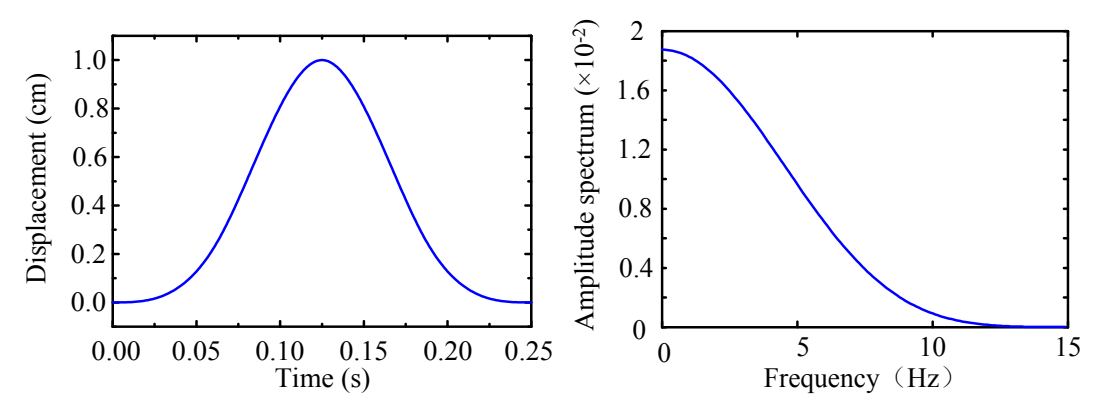

Figure 4. Time-history of incident wave and its Fourier spectrum, respectively.

\section{SIMULATION RESULT}

\subsection{Snapshots of the Wave Field}

The wave propagation behavior was analyzed by computing the displacement snapshots with durations of $20 \mathrm{~s}$ (low-pass filtered with a corner frequency of $10 \mathrm{~Hz}$ ). Figure 5 shows the snapshots of the displacement wave field at every $0.5 \mathrm{~s}$, from $0.5 \mathrm{~s}$ to $3.0 \mathrm{~s}$, for the Dirac impulse input motion with different incident angles. In the beginning, ground shaking is not obvious. When the wave enters the Wudu Basin, the travel time of the wave fronts slow down and are dramatically distorted compared with those outside the basin because of low shear wave speeds in the basin, particularly within the soft sedimentary layer. Surface waves that propagate after the $\mathrm{S}$ wave can be observed. Surface waves are generated by reflections and mode conversions at the shallow basin edges and free surface. Yalcinkaya and Alptekin (2005) illustrates similar contributions of basin edge-induced surface waves to site amplifications. At the same time, the energy is trapped and reflected within the low-wave speed sediments. This effect is particularly clear around the basin where the basement is close to the ground surface and has a large wave speed contrast relative to the hard rock. However, P wave energy is relatively weak at this moment and passes through the basin quickly as compared with the later $\mathrm{S}$ wave and surface wave phases.

When the main body wave phases propagated out of the basin, the basin continues to shake for several seconds. This longer shaking comes from two different seconds: the energy is trapped and reflected within the low-wave-speed sediments as described previously and the energy is reflected and waves are generated by scattering from the basin edges. However, the characteristics of the earthquake motion vary with the different incident angles. With the increase of the incident angle, the seismic energy takes a longer time to reach the basin. 

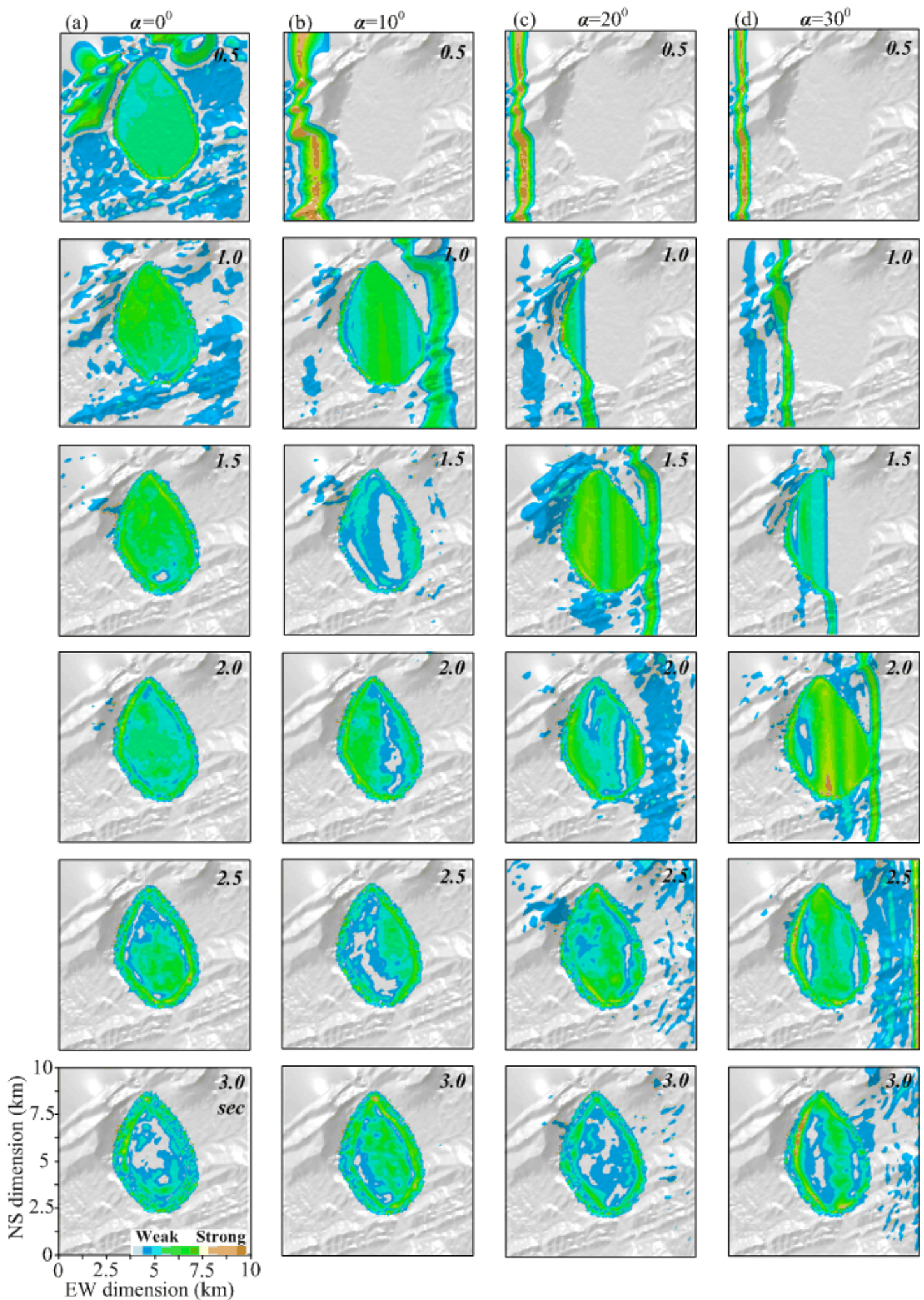

Figure 5. Snapshots of the wave field at the surface from $0.5 \mathrm{sec}$ to $3.0 \mathrm{sec}$. Twenty-four meaningful snapshots are shown. They are (a)0.5th, (b) 1.0th, (c) 1.5th, (d) 2.0th, (e) 2.5th and (f) 3.0th sec with different incident angles: $\alpha=0^{\circ}, 10^{\circ}, 20^{\circ}, 30^{\circ}$, respectively, calculated by the FEM. 


\subsection{Simulating Waveform}

The simulating waveforms along profile $\mathrm{AA}^{\prime}$ shown in Figure 2 were analyzed to determine how the waves are influenced by the incident angles quantitatively. A total of 61 receivers were placed on the free surface, spaced at $0.1 \mathrm{~km}$ intervals along profile $\mathrm{AA}^{\prime}$, in which site points 2, 3, and 4, which were located in the basin; site points 1 and 5 are located outside the basin (from west to east are marked as sites 1 to 5). Figure 6 shows the response along profile $\mathrm{AA}^{\prime}$ with each component normalized by its maximum value.
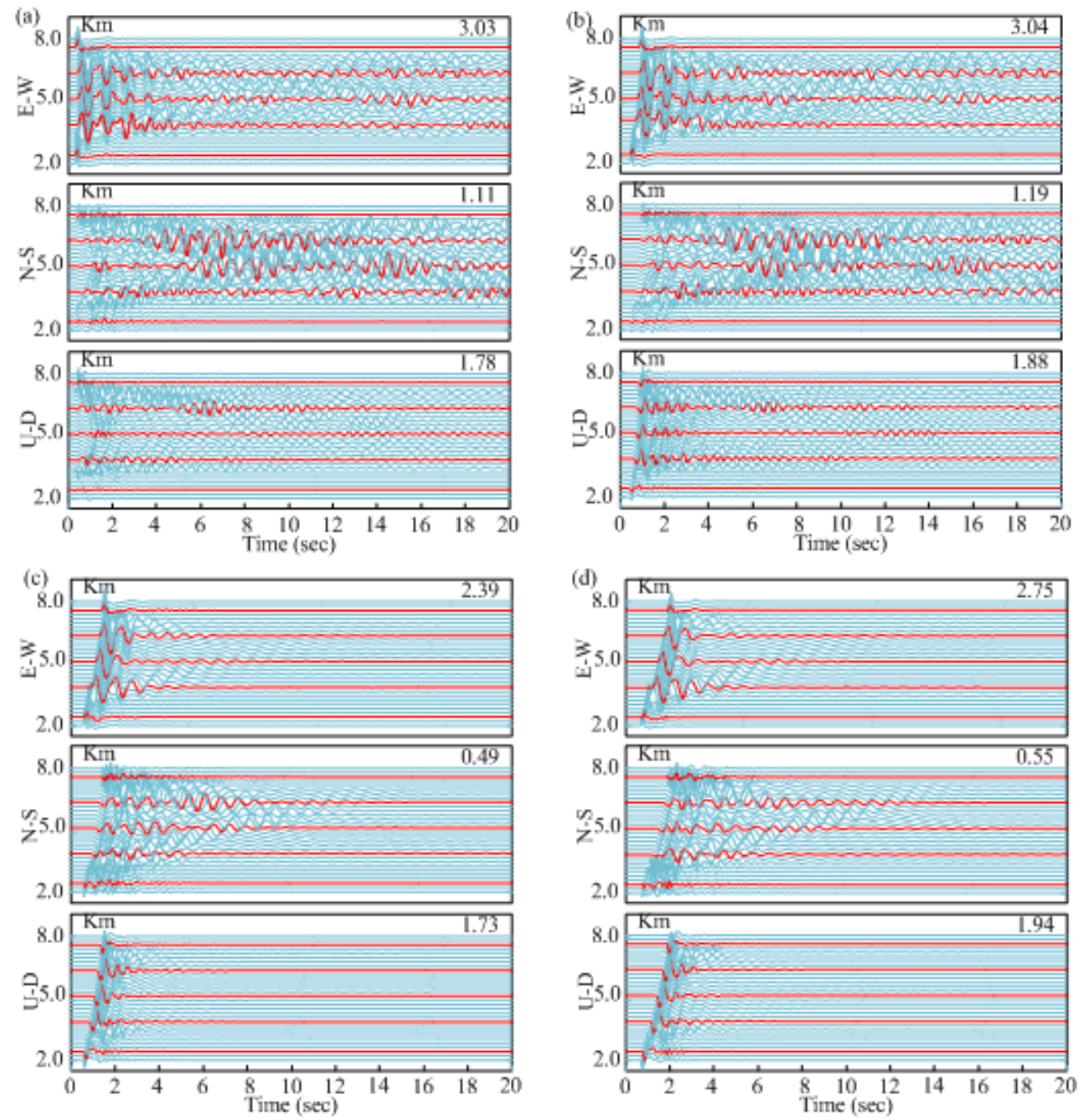

Figure 6. Synthetic seismograms record section along the profile AA' (shown in Figure 2) with different incident angles: (a) $\alpha=0^{\circ}$, (b) $\alpha=10^{\circ}$, (c) $\alpha=20^{\circ}$, and (d) $\alpha=30^{\circ}$, respectively. Each component's set of seismograms is normalized to its maximum value, which is denoted in the right corner. The unit of amplitude is $\mathrm{cm}$.

These waveforms show anomalous amplification effects in the basin. Notably, the simulating waveforms in the basin have a relatively longer duration than those outside the basin, particularly for the records at site point 5, which is at the center of the $\mathrm{AA}^{\prime}$ line. The ground motion in the horizontal direction is more complicated than that in the vertical direction; the maximum value of the peak displacement in the E-W component is larger than that in the UD component, and the U-D component is larger than the N-S component. Smaller amplitudes of the $\mathrm{P}$ wave inside the basin in the U-D component were observed; the basin-induced scattered wave propagates toward the east direction, as observed from the moving out of the scat- 
tered wave. These scattered amplitudes gradually decrease with time. For incident angle $0^{\circ}$, the basin-focusing effect in the middle part of profile $\mathrm{AA}^{\prime}$ and the symmetric pattern of the basin-induced scattered wave propagation were observed because a part of the scattered wave energy is reflected back to the basin; the remainder passes through to the outside of the basin. When the incident angle is $10^{\circ}$, the area where the basin-focusing effect rises is in the eastern part of profile $\mathrm{AA}^{\prime}$. However, when the incident angles are $20^{\circ}$ and $30^{\circ}$, the basin-focusing effect is unclear and the duration of the ground motion is obviously reduced. This finding indicates that the surface wave generated from the eastern part of the basin decreases with the increase of the incident angle.
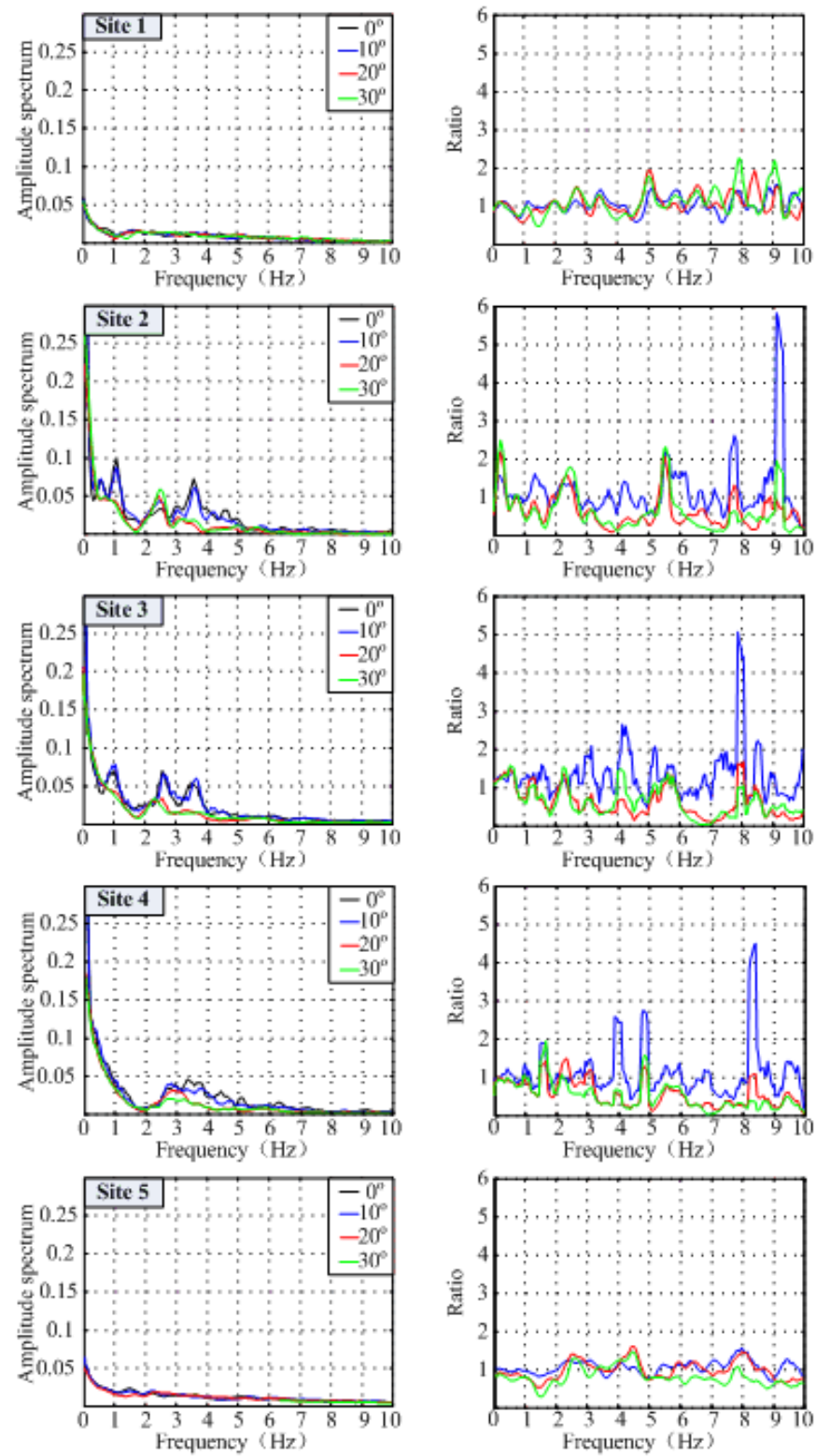

Figure 7. Comparison of Fourier spectra for the sites with different incident angles (left-hand column) and the spectral magnification relative with respect to vertical incidence (right-hand column). (The Sites was noted in the Figure 2).

Figure 7 presents the amplitude spectrum of site point 1 to 5 under different incident angles and the spectral amplitude relative magnification with respect to the vertical incidence. Overall, different site points under different incident angles are sensitive to different frequencies. 
At the same frequency, the spectral amplitude of the site points in the basin is larger than the other site points. For the site points in the basin, the spectral amplitude relative magnification initially increases and then decreases with the increase of the incident angle. When the incident angle is $10^{\circ}$, the amplification factor is the largest. However, for the site points at the outside of the basin, the spectral amplitude relative magnification changed slightly with the increase of the incident angle.

\subsection{Peak Ground Motion Distribution}

The maximum particle displacement within the records was analyzed to obtain information on the peak ground displacement (PGD) distribution. A comparison of the spatial variation of the PGD distribution in the E-W, N-S, and U-D components under different incident angles, namely, (a) $\alpha=0^{\circ}$, (b) $\alpha=10^{\circ}$, (c) $\alpha=20^{\circ}$, and (d) $\alpha=30^{\circ}$, is shown in Figure 8 . The relative change in PGD along profile $\mathrm{AA}^{\prime}$ is shown in Figure 8.

(a)

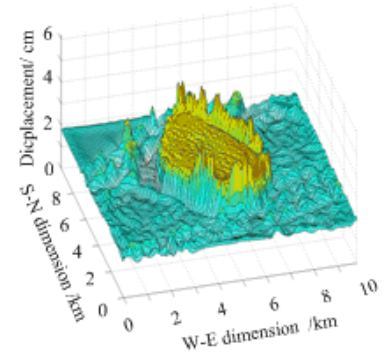

(b)

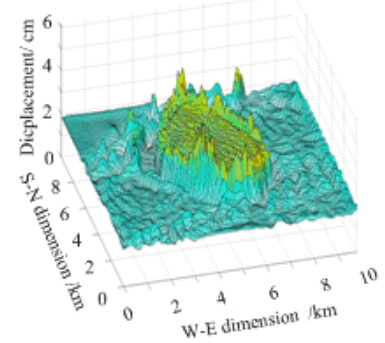

(c)

(d)
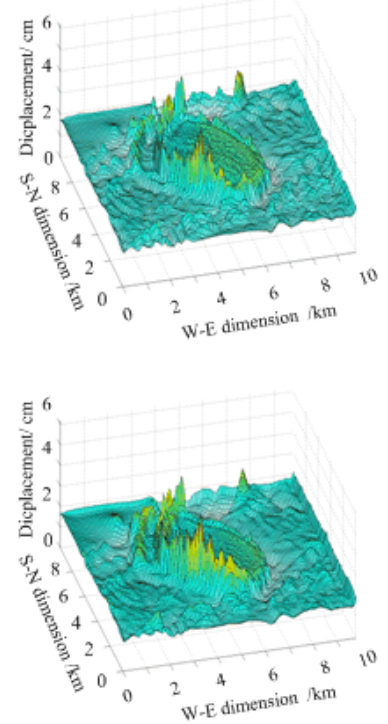

$\mathrm{N}-\mathrm{S}$ component
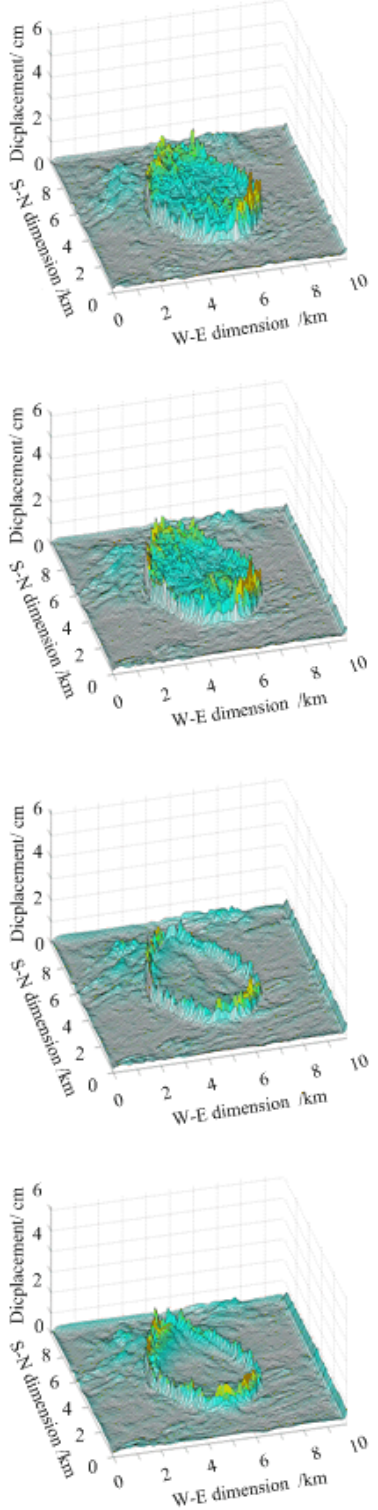
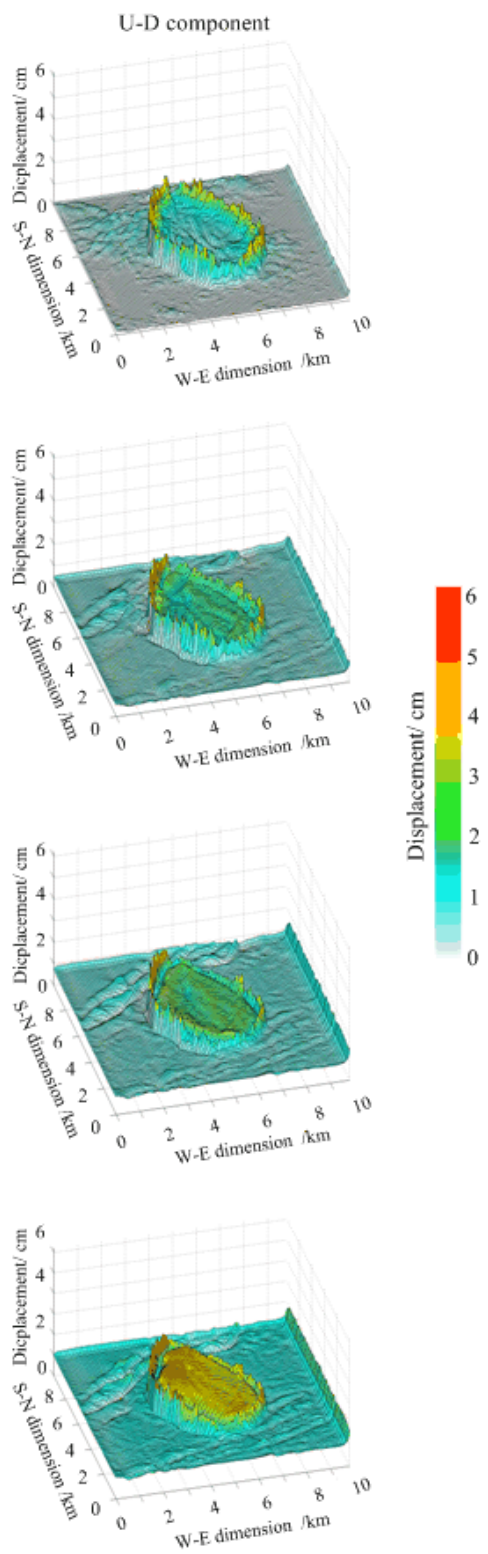

Figure 8. The PGD distribution derived from simulation results with different incident angles: (a) $\alpha=0^{\circ}$, (b) $\alpha=10^{\circ}$, (c) $\alpha=20^{\circ}$, and (d) $\alpha=30^{\circ}$, respectively. (Note: the number of contours are the same with the different incident angles). 
Figure 8 indicates that ground motions in the Wudu Basin have PGD values that are close to $6 \mathrm{~cm}$, which is larger than that observed in the mountainous areas, where the PGD is $2 \mathrm{~cm}$ on average. First, the incident angle of $0^{\circ}$ was analyzed (Fig. 8a). In the basin, most of the large PGD values occur at the edge of the basin. The Wudu Basin shows relatively large PGD values in the $\mathrm{E}-\mathrm{W}, \mathrm{N}-\mathrm{S}$, and $\mathrm{U}-\mathrm{D}$ components compared with the surrounding regions because of low-wave speed sediments in the basin. Outside the basin, complex PGD patches are observed in the mountainous areas, particularly in the mountain of flowers and fruit. Figure 8a illustrates that topography increases the PGD values at mountain tops and ridges, whereas valleys usually decrease the PGD. Lee et al. $(2008,2009)$ illustrates a similar phenomenon by analyzing the simulated ground motions in mountainous areas surrounding the Taipei basin. In the three components, the PGDs at the edge of the basin are larger than those in the basin: in the E-W component, the largest PGD values occur at the south part of the basin between the mountain of Jingtai and the outlet of the Fujiang River; in the N-S component, the largest PGD values occur at the southeastern margin of the basin; and in the U-D component, the PGDs are symmetric distributions at the edge of the basin.

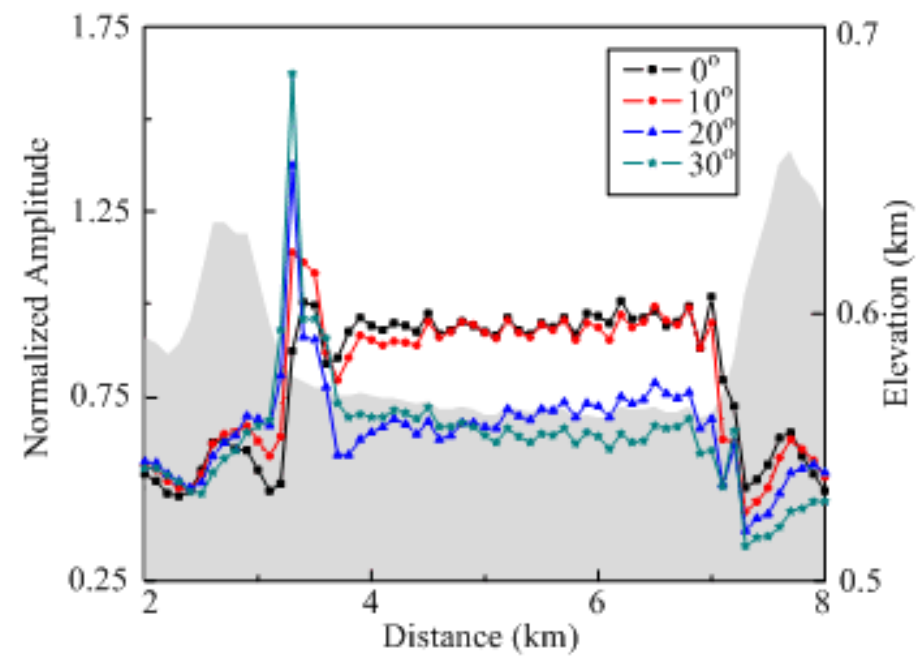

Figure 9. The PGD distribution along the profile AA' with different incident angles: $\alpha=0^{\circ}, 10^{\circ}, 20^{\circ}$, and $30^{\circ}$, respectively (Normalized by the maximum value of the PGD recorded on the AA' line when the wave vertical incident). The background map show the topography.

With the increase of the incident angle, the PGD values in the entire simulation area reduced in the $\mathrm{E}-\mathrm{W}$ and $\mathrm{N}-\mathrm{S}$ components; however, the PGD values increased in the $\mathrm{U}-\mathrm{D}$ component with the increase of the incident angle. When the incident angle is greater than $10^{\circ}$, the PGD values in the west part of the basin have a faster reduction than the eastern part in the E-W and N-S components, whereas the PGD values in the western part of the basin have a faster increase than those in the eastern part in the U-D component. The PGD values along profile $\mathrm{AA}^{\prime}$ were analyzed to quantify the effects of topography for different incident angles . When the seismic wave has a vertical incidence, the ground motions in the Wudu Basin have PGD values that are close to $3.05 \mathrm{~cm}$, which is larger than that observed outside the basin (where the value is $1.87 \mathrm{~cm}$ ). The change of PGD basically has no change in most of the basins, is $2.83 \mathrm{~cm}$ on average, and has almost a symmetrical distribution. Figure 9 shows the PGD distribution with different incident angles and is normalized by the maximum value of the PGD recorded on the $\mathrm{AA}^{\prime}$ line when the wave has a vertical incident. In the case of $10^{\circ}$, PGD values exhibit a larger increase at the west side of the basin margin compared with the case of the vertical incidence, where only a slight change occurs compared with the rest of the basin. However, when the incident angle is greater than $10^{\circ}$, the PGD values in the basin are 
2.32 and $2.29 \mathrm{~cm}$ on average. Compared with the case of the vertical incidence, the PGD values are reduced by $18.24 \%$ and $19.29 \%$. The largest PGD values occurred at the same site. By contrast, the PGD values are increased by $23.75 \%$ and $52.78 \%$

\subsection{Cumulative Kinetic Energy}

Olsen et al. $(1995,1996)$ considered the cumulative kinetic energy parameter $\left(E_{k}\right)$. $E_{k}$ can reflect the amplitude and duration time of the total motion that may be more closely related to the potential damage from shaking. The cumulative kinetic energy per unit volume of the $k$ th component trace is expressed as:

$$
E_{k}=\frac{1}{2} \rho(x, y, z) \int \dot{u}_{k}^{2}(x, y, z, t) d t
$$

The distribution of $E_{k}$ is shown in Figure 10. In our simulation, $E_{k}$ at mountain tops and ridges increases dramatically, and the distribution of $E_{k}$ at valleys and flat parts on hills is similar to the PGD with different incident angles. However, the energy in the basin and the basin edge is more complex than that outside of the basin and unusually large in the west side of the basin edge with the increase of the incident angle, particularly when the incident angle is $30^{\circ}$. Most of the energy is trapped and reflected in the west side of the basin edge with the increase of the incident angle.
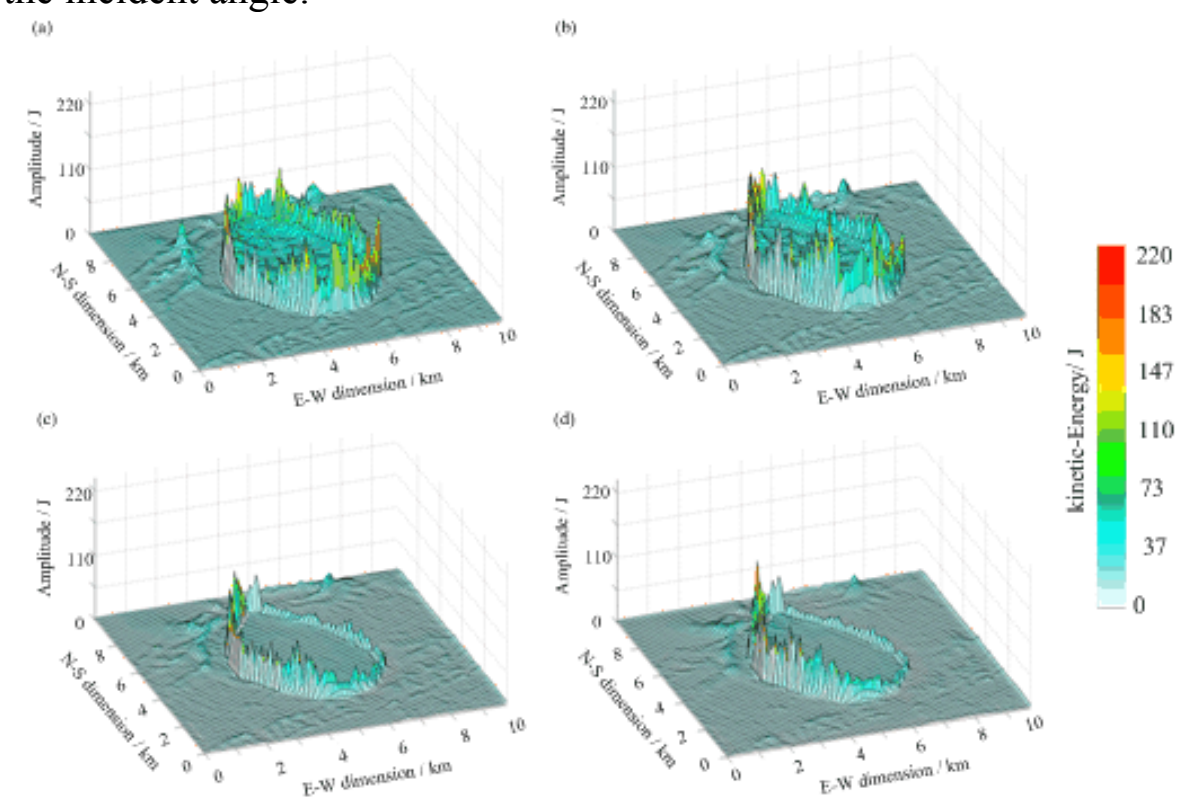

Figure 10. The cumulative kinetic energy distribution with different incident angles: (a) $\alpha=0^{\circ}$, (b) $\alpha=10^{\circ}$, (c) $\alpha=20^{\circ}$, and (d) $\alpha=30^{\circ}$, respectively.

The $E_{k}$ value along profile $\mathrm{AA}^{\prime}$ shown in Figure 11 was analyzed to examine the detailed difference among the four incident angles. The cumulative kinetic energy was normalized by the maximum value of the energy recorded in profile $\mathrm{AA}^{\prime}$ when the wave has a vertical incident. When the incident angle is $10^{\circ}$, the cumulative kinetic energy in the basin is larger than the vertical incident, which is different from the distribution of PGD. With the increase of the incident angle, the cumulative kinetic energy at the west edge of the basin increases gradually, whereas the cumulative kinetic energy at the eastern edge of the basin decreases, which is similar to the PGD. 


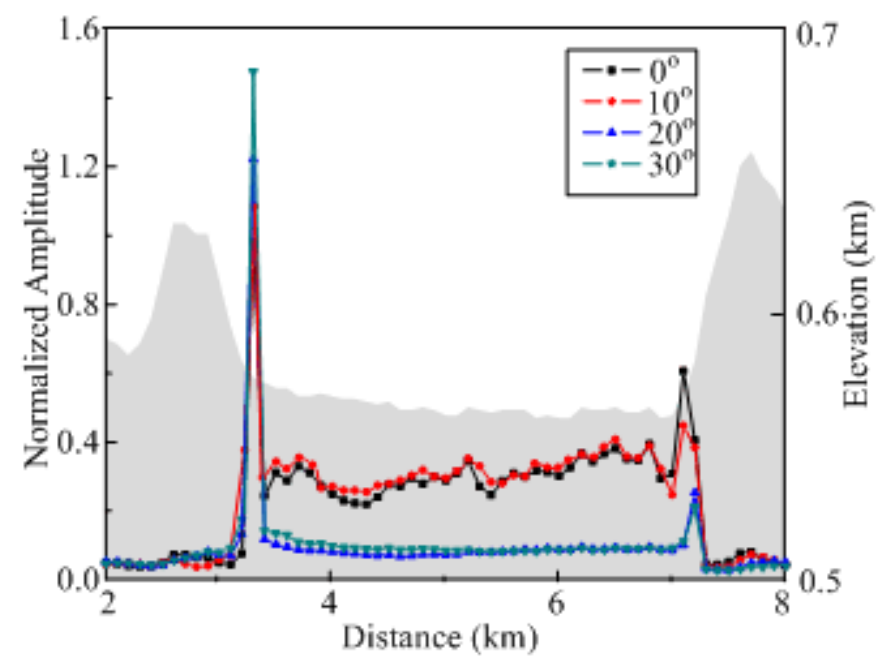

Figure 11. Cumulative kinetic energy distribution along the profile AA' with different incident angles: $\alpha=0^{\circ}, 10^{\circ}$, $20^{\circ}$, and $30^{\circ}$, respectively (Normalized by the maximum value of the energy recorded on the profile AA' when the wave vertical incident). The background map show the topography.

\section{CONCLUSIONS}

The 3D model of the Wudu Basin was established based on the regional geological survey borehole data of spatial distribution and the DTM data. Grid partition was achieved by the special preprocessor software HyperMesh. A careful mesh was used to accommodate the steep topography and the complex geometry of the Wudu Basin. The distance between the points at the shallowest part of the FEM mesh was approximately $2.5 \mathrm{~m}$, which enabled the inclusion of realistic topography from the DTM data and was sufficient to calculate the response of seismic waves up to a maximum frequency of approximately $10 \mathrm{~Hz}$. The viscous spring artificial boundary was chosen as the artificial condition, and the earthquake motion of the oblique incidence was transformed into the equivalent nodal forces acting on the viscous spring artificial boundary of the finite model.

The numerical results illustrated that the PGD increases at mountain tops and ridges, whereas the PGD usually decreases in valleys. The topographic effects also strongly depend on the directivity of the event. At most of the basin boundary, the dip angle is less than $45^{\circ}$. For the vertical incident seismic wave, topography scatters the body waves, which subsequently propagates as surface waves and spreads into the Taipei basin. These waves further interact with the basin and the surrounding mountains, finally resulting in complex amplification. The angles between the seismic wave propagation direction and the interface on the east side of the basin edges decreased with the increase of the incident angle of the seismic waves. This phenomenon leads to a reduction in the surface wave energy from the eastern edge of the basin. By contrast, the surface wave energy is enhanced on the west side of the basin. The result revealed different amplifications at the same site.

Although the seismic waves considered in this study are relatively simple compared with a real earthquake, these findings are based on hypothetical earthquake events in the Wudu Ba$\sin$. The simulations show that topography has different effects depending on the scenario: it may or may not reduce ground motion in Wudu depending on the directivity of the event. These results illustrate the fact that the topography and the incident angle of seismic waves should be considered when assessing seismic hazards. 


\section{ACKNOWLEDGEMENTS}

This research work is supported by the National Key Research and Development Program of China (2016YFC402800), National Natural Science Foundation of China (41374049, 51421005), China National Innovation Talent Promotion Program (2013RA4024), and China National High-level personnel of special support program.

\section{REFERENCES}

[1] Alex, C.M., and K. B. Olsen (1998). Lens-effect in Santa Monica, Geophys. Res. Lett. 25, 3441-3444.

[2] Assimaki, D., G. Gazetas, and E. Kausel 2005. Effects of local soil conditions on the topographic aggravation of seismic motion: parametric investigation and recorded field evidence from the 1999 Athens earthquake, Bull. Seismol. Soc. Am. 95, 1059-1089.

[3] Bao, H., Bielak, J., Ghattas, O., Loukas, F., Kallivokas, D.R., O’Hallaron, J.R., 1998. Large scale simulation of elastic wave propagation in heterogeneous media on parallel computers. Comp. Meth. Appl. Mech. Eng. 152, 85-102.

[4] Davis, P. M., J. L Rubinstein, K. H. Liu, S. S. Gao, and L. Knopoff (2000). Northridge earthquake damage caused by geologic focusing of seismic waves, Science289, 17461750 .

[5] Du XL, Zhao M, Wang JT. A stress artificial boundary in FEA for near-field wave Problem. Chinese Journal of Theoretical and Applied Mechanics 2006; 38(1):49-56.

[6] Faccioli, E., Maggio, F., Paolucci, R., Quarteroni, A., 1997. 2D and 3D elastic wave propagation by a pseudo-spectral domain decomposition method. J.Seismol.1,237-251.

[7] Graves, R. W. (1998). Three-dimensional finite-difference modeling of the San Andreas fault: source parameterization and ground-motion levels, Bull. Seismol. Soc. Am. 88, 881-897.

[8] Hang J Q. Study on Nonlinear Seismic Response of Rock Tunnels [D].Beijing: College of Architecture and Civil Engineering of Beijing University of Technology, 2015.

[9] Hartzell, S. H., D. L. Carver, and K. W. King 1994. Initial investigation of site and topographic effects at Robin wood Ridge, California, Bull. seism. Soc. Am. 84, 13361349.

[10] Komatitsch, D., Q. Liu, J. Tromp, P. Suss, C. Stidham, and J. H. Shaw (2004). Simulations of ground motion in the Los Angeles basin based upon the spectral-element method, Bull. Seismol. Soc. Am.94, 187-206.

[11] Kristek, J., Moczo, P., Pazak, P., 2009. Numerical modeling of earthquake motion in Grenoble basin, France, using a 4th-order velocity-stress arbitrary discontinuous staggered-grid FD scheme, in ESG 2006. In: Bard, P.-Y. Chaljub, E., Cornou, C., Cotton, F., Gueguen, P. (Eds.), Third Intl. Symposium on the Effects of Surface Geology on Seismic Motion, LCPC Editions, ISSN 1628-4704, vol. 2, pp.1517-1526.

[12] Lee, S. J., H. W. Chen, Q. Liu, D. Komatitsch, B. S. Huang, and J. Tromp (2008). Three-dimensional simulations of seismic wave propagation in the Taipei basin with realistic topography based upon the spectral- element method, Bull. seism. Soc. Am. 98, 253-264, doi 10.1785/0120070033. 
[13] Lee, S.J., Chan, Y.C., Komatitsch, D., Huang, B.S. \& Tromp, J., 2009a. Effects of realistic surface topography on seismic ground motion in the Yangminshan region of Taiwan based upon the spectral-element method and LiDAR DTM, Bull. seism. Soc. Am., 99(2A), 681-693.

[14] Lee, S.J., Komatitsch, D., Huang, B.S. \& Tromp, J., 2009b. Effects of topography on seismic wave propagation: an example from northern Taiwan, Bull. seism. Soc. Am., 99(1), 314-325.

[15] Liu, S.W., Datta, S.K., Bouden, M., 1991. Scattering of obliquely incident seismicwaves by a cylindrical valley in a layered half space. Earthq. Eng. Struct. Dyn. 20,859-870.

[16] Liu JB, Lu YD. A direct method for analysis of dynamic soil-structure interaction based on interface idea. Developments in Geotechnical Engineering 1998; 83:261-276.

[17] Liu JB, Du YX, Du XL, Wang ZY, Wu J. 3D viscous-spring artificial boundary in time domain. Earthquake Engineering and Engineering Vibration 2006; 5(1):93-102. DOI: 10.1007 / s1 1803-006-0585-2.

[18] Liu JB, Gu Y, Li B, Wang Y. An efficient method for the dynamic interaction of open structure-foundation systems. Frontiers of Architecture and Civil Engineering in China 2007; 1(3):340-345. DOI:10.1007/s11709-007-0045-8.

[19] Ma, S., R. J. Archuleta, and M. T. Page (2007). Effects of large-scale surface topography on ground motions, as demonstrated by a study of the San Gabriel Mountains, Los Angeles, California, Bull. seism. Soc. Am. 97, 2066-2079, doi 10.1785/0120070040.

[20] Moczo, P., J. Robertsson, and L. Eisner 2007. The finite-difference time domain method for modeling of seismic wave propagation, Adv. Wave Propag. Heterog. Earth 48, 421516.

[21] Olsen, K. B., R. J. Archuleta, and J. R. Matarese (1995). Three-dimensional simulation of a magnitude 7.75 earthquake on the San Andreas fault, Science 270, 1628-1632.

[22] Olsen, K. B., J. C. Pechmann, and G. T. Schuster (1996). An analysis of simulated and observed blast records in the Salt Lake basin, Bull Seismol. Soc. Am. 86, 1061-1076.

[23] Olsen, K.B., (2000). Site amplification in the Los Angeles basin from three dimensional odeling of ground motion. Bull. seism. Soc. Am. 90 (6B), S77-S94.

[24] Pitarka, A., (1999). 3D elastic finite-difference modeling of seismic motion usingstaggered grids with nonuniform spacing. Bull. seism. Soc. Am. 89, 54-68.

[25] Spudich, P., M. Hellweg, and W. H. K. Lee (1996). Directional topographic site response at Tarzana observed in aftershocks of the 1994 Northridge, California, earthquake: implications for main shock motions, Bull. seism. Soc. Am. 86, no. 1B, S193S208.

[26] Taborda, R., Bielak, J., Restrepo, D., (2012). Earthquake ground-motion simulation including nonlinear soil effects under idealized conditions with application to two case studies. Seismo. Res. Lett.83, 1047-1060. 